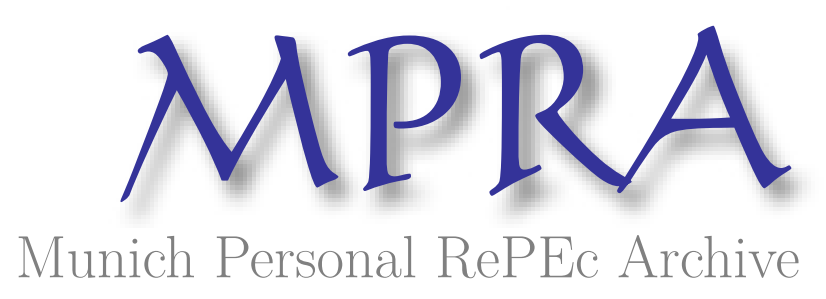

Exchange rates of oil exporting countries and global oil price shocks: A nonlinear smooth-transition approach

Haug, Alfred A. and Basher, Syed Abul

7 December 2017

Online at https://mpra.ub.uni-muenchen.de/83205/

MPRA Paper No. 83205, posted 10 Dec 2017 23:34 UTC 


\title{
Exchange rates of oil exporting countries and global oil price shocks: A nonlinear smooth- transition approach
}

\author{
Alfred A. Haug* \\ Department of Economics, University of Otago, PO Box 56, Dunedin 9054, New Zealand \\ Email: $\underline{\text { alfred.haug@otago.ac.nz }}$ \\ Syed Abul Basher \\ Department of Economics, East West University, Plot No - A/2, Aftabnagar Main Road, \\ Dhaka 1212, Bangladesh \\ Email: syed.basher@gmail.com
}

\begin{abstract}
This paper considers logistic (asymmetric) and exponential (symmetric) smooth transition adjustments of real and nominal exchange rates for six major oil-exporting countries in response to different shocks affecting oil prices. Real exchange rate movements affect the terms of trade and hence may affect relative competitiveness. We detect no statistically significant non-linearities for the adjustment process of real exchange rate returns, be they asymmetric or symmetric, in response to oil supply shocks, idiosyncratic oil-market-specific shocks, and speculative (crude oil inventory) oil-market shocks. On the other hand, global aggregate demand shocks, which are shocks that do not directly originate in the oil market, have nonlinear asymmetric effects on real exchange rate returns for Canada, Mexico, Norway and Russia, and linear effects for the UK. These qualitative results mostly hold for nominal exchange rate returns as well. Exceptions are that linear effects are found for aggregate demand shocks for Brazil and for idiosyncratic shocks for Norway, whereas the aggregate demand shocks for the UK have nonlinear and asymmetric effects instead of linear ones.
\end{abstract}

JEL Classification: F31, Q43

Keywords: Logistic and exponential smooth transition; oil price shocks; exchange rates.

Declarations of interest: none.

*Corresponding author: Alfred A. Haug, Department of Economics, University of Otago, PO Box 56, Dunedin 9054, New Zealand. Telephone: +64-3-470-5636. 


\section{Introduction}

A large number of studies explored the empirical relationship between oil prices and exchange rates with mainly three different types of econometric tools: linear cointegration methods, linear and nonlinear Granger-causality tests, and linear vector autoregression (VAR) models. For example, Amano and van Norden (1998) used linear cointegration tests and Granger causality tests and found a positive long-run relationship between real oil prices and US-dollar exchange rates. However, Reboredo (2012) found instead weak evidence for co-movements between nominal oil prices and exchange rates of several oil exporting and oil importing countries. Linear and nonlinear correlations and copula functions for symmetric and asymmetric co-movements, which may vary over time, were considered.

In a seminal paper Kilian (2009) showed that the impact of an oil price change on the economy depends upon whether the oil price change is due to an oil supply shock, a global aggregate demand shock, or an oil-market-specific demand shock. Numerous studies followed using Kilian's (2009) framework to analyze the effects of these oil-market shocks on macroeconomic and financial variables in various countries. Atems et al. (2015) and Basher et al. (2016) used Kilian's (2009) methodology in order to study the effects of these oil-market shocks on exchange rates. Atems et al. (2015) found that whether US exchange rates respond asymmetrically to oil-market shocks depends on the size and sign of a shock, using an exchange rate model with otherwise linear relationships. Basher et al. (2016) used instead a nonlinear Markov-switching model for exchange rates and found only limited evidence that oil supply shocks affect exchange rates, whereas global aggregate demand shocks played an important role. ${ }^{1}$

There is an ongoing debate in the literature about whether the effects of oil price shocks have linear or nonlinear effects on other macroeconomic variables. Mork (1989) argued that increasing real oil prices have significantly different effects on US real GDP growth compared to declining oil prices. Hamilton $(1996,2003)$ used a net oil price increase to model effects of oil prices. His net oil price measure is defined as observed oil price increases that represent new highs relative to the recent experience, or reversals of recent decreases, and zero values in other periods without

\footnotetext{
${ }^{1}$ The regime classification measures (RCMs) for the fit of the Markov-switching models reveal relatively large values for oil exporting countries, indicating room for improvements in nonlinear modelling by using alternative models. The Markov model with $t$-distributed innovations seems to achieve a low value (of 7.84 in Table 6, p. 21) only for Russia. Other values for oil exporters in Table 6 range from 39.30 (UK) to 74.07 (Canada) and from 22.46 (UK) to 86.66 (Norway) in Table 5 (p. 19) for normally distributed innovations. The RCM can take values from 0 (perfect regime classification) to 100 (no regime classification is detected).
} 
such changes. On the other hand, Kilian and Vigfusson (2011a, 2011b) discussed econometric issues in regard to oil price shocks and presented empirical evidence in favor of effects on output being linear and symmetric. ${ }^{2}$ Instead, a threshold model, say with smooth transition between regimes, allows estimating the adjustment process itself from the data without imposing a strict formula for switches as Hamilton's net oil price does. Flexible nonlinear functional forms can be specified for alternative processes for such smooth transition regression models that are symmetric or asymmetric for adjustments in response to negative and positive changes (Teräsvirta et al., 2010). An alternative nonlinear model is a Markov-switching model that determines regimes from the data as well, pursued in Basher et al. (2016) and Basher et al. (2017).

In this paper, we employ a nonlinear smooth transition model for modelling the effects of oilmarket shocks on exchange rates. In contrast to Markov-switching models where the adjustment process is abrupt and in a way a "black box," smooth transition models specify the functional form of the adjustment process and are explicit about what variables drive the process. These types of smooth transition models have been successfully used to model the time series behavior of exchange rate movements (see, e.g., and Kilian and Taylor, 2003, and Taylor et al., 2001) but have not yet been used to explain how exchange rates react to changes in oil prices, as far as we know.

Kilian and Murphy (2014) extended the oil-market model of Kilian (2009) by including as an additional variable changes to above-ground global crude oil inventories. This allows for explicit identification of oil-market shocks due to speculative trading in the crude oil market. We employ both models to derive the oil-market shocks: Kilian's (2009) model and alternatively the extended oil-market model of Kilian and Murphy (2014). The latter model allows to separate the oil-marketspecific demand shock in Kilian (2009) into an idiosyncratic oil-market-specific demand shock and an explicitly identified speculative (crude oil inventory) demand shock. We follow Kilian (2009) and apply a two-stage approach to examine the response of the real exchange rate to oil price shocks. We first estimate a structural VAR model with monthly data, following (i) Kilian (2009) with a Cholesky identification scheme and (ii) Kilian and Murphy (2014) by imposing contemporaneous and dynamic sign restrictions and bounds for short-run price elasticities of oil production and "demand for oil in use" in order to identify structural oil-market shocks. We then analyze the impact of these shocks on exchange rates in second-stage regressions.

\footnotetext{
${ }^{2}$ See the reply by Hamilton (2011). For a comprehensive recent study with different definitions of net oil price increases see Herrera et al. (2016).
} 
We consider as a transition variable in the nonlinear model, in turn, each of the oil-market shocks. The transition variable triggers the transition from one regime to another and allows for a smooth transition, or abrupt transition as a limiting case. The logistic form renders asymmetric transitions so that positive and negative shocks can have different transition paths. On the other hand, the exponential transition function renders symmetric transition paths for positive and negative shocks. The potential nonlinearity takes two forms that have been used commonly and successfully for nonlinear modelling in economics and finance. ${ }^{3}$

Most of the literature on the effects of oil price changes has concentrated on the US economy. A good number of papers studied oil-importing countries but there are only a few that considered oil-exporting countries. This paper contributes to the literature on the effects of oil price changes for developed and emerging oil-exporting countries by allowing for potentially nonlinear effects on real exchange rates, which affect a country's terms of trade and therefore may affect its competitiveness. We choose for our analysis major net oil exporting countries for which sufficient data for flexible exchange rate periods are available: Canada, Brazil, Mexico, Norway, Russia, and the UK. ${ }^{4}$ These countries are among the top twenty crude oil exporters in 2009 (Europe's Energy Portal, 2016) and comprise developed (Canada, Norway, and the UK) as well as emerging economies (Brazil, Mexico, and Russia).

The paper is organized as follows. Section 2 provides a brief review of the related literature on exchange rates and Section 3 describes the econometric models, the data and presents the results. Section 4 concludes the paper.

\section{Related literature: a brief review}

The theoretical literature on exchange rates considered two channels through which an oil price shock can be transmitted to a country's exchange rate: the terms of trade channel and the wealth effect channel. The terms of trade channel was explored, for example, by Backus and Crucini (2000), and Chen and Rogoff (2003). For oil-exporting countries, an increase in oil prices generally leads to improvements of the trade balance and subsequently to an appreciation of the local currency, which may eventually lead to a Dutch Disease problem by driving up the price of

\footnotetext{
${ }^{3}$ See Granger and Teräsvirta (1993), Teräsvirta (1994, 1998), Teräsvirta et al. (2010), and Ma and Wohar (2014).

${ }^{4}$ For most of the estimation period the UK was a net crude oil exporter, except since 2005 when it became a net importer. See https://www.eia.gov/todayinenergy/detail.cfm?id=16971.
} 
the non-tradable goods (Buetzer et al., 2012). Empirical support for this view was presented by Backus and Crucini (2000), showing that oil price changes determine most of the variation in the terms of trade.

The distinction between oil-exporting and oil-importing countries appears particularly important for the wealth effect channel. An increase in oil prices is associated with a wealth transfer from oil-importing to oil-exporting countries that leads to a real appreciation of the exchange rates of the oil-exporting country due to portfolio reallocations (e.g., Buetzer et al., 2012, and Fratzscher et al., 2014). The basic theory for the wealth channel was developed by Golub (1983) and Krugman (1983), and related empirical evidence was presented in Kilian et al. (2009) and Bodenstein et al. (2011), among others.

Early research on the relationship between oil prices and exchange rates commonly applied linear cointegration methods and Granger causality tests. Numerous studies reported finding evidence of an appreciation of the US dollar in response to rising oil prices. In reviewing the large and growing literature on the relationship between exchange rates and oil prices, Coudert et al. (2011) found a long-run elasticity between oil prices and exchange rates of 0.3 for oil exporting countries. In contrast to these studies, Buetzer et al. (2012) used the two-step approach of Kilian (2009) for assessing the impact of oil price shocks on exchange rates. They analyzed in a linear framework their impact on nominal and real exchange rates, as well as stock returns, for 44 advanced and emerging countries. Oil supply and global aggregate demand shocks are found to not systematically lead to an appreciation of oil exporters' currencies relative to oil importers', contrary to the predictions of theory. On the other hand, oil-market specific demand shocks do exert pressure on oil exporters' currencies to appreciate. Basher et al. (2012) extended Kilian's (2009) three-variable linear structural VAR model of the crude oil market to include other key macroeconomic variables and found no significant effects of oil supply shocks on exchange rates, whereas an unanticipated global demand expansion lead to a depreciation of the US dollar. Furthermore, the impact of a positive oil-market-specific demand shock was also negative (reflecting the so-called numeraire effect). These findings supported the conclusion that exchange rate movements are determined primarily by current account movements (Krugman, 1983).

Atems et al. (2015) studied the role of Kilian's (2009) oil-market shocks for real and tradeweighted exchange rates for net oil importers and exporters. They separated each of the three oilmarket shocks into negative and positive shocks and alternatively into large and small shocks and 
considered linear adjustment processes for these shocks. Basher et al. (2016) explored instead nonlinearities for the adjustment effects of the three oil-market shocks on real exchange rates of oil exporters and importers. The nonlinearities were modelled in the form of Markov-type regime changes, however, the model fit was somewhat questionable for oil exporting countries (see footnote 1). Atems et al. (2015) and Basher et al. (2016) found that global oil supply shocks have generally no statistically significant, or only very limited effects, on real exchange rates. They further found that positive oil-market-specific demand shocks usually lead to an appreciation of currencies of oil-exporting countries but these effects are at times borderline cases for the $95 \%$ confidence bands reported. On the other hand, global aggregate demand shocks generally had statistically significant effects on real exchange rates in both studies, but a clear pattern did not always emerge for oil-exporting countries.

\section{Econometric methodology, data, and results}

\subsection{Modelling nonlinear smooth adjustment}

An important advantage of smooth transition models, in comparison to other available nonlinear models, is that nonlinear models can be specified in a relatively parsimonious way so that only a small number of parameters needs to be estimated and samples do not have to be particularly large to achieve reliable statistical inference. Hamilton (2016) surveyed and compared various nonlinear econometric models, i.e., models with regime changes, available in the literature, and pointed out (pp. 33-34) that smooth transition models allow basing the changes in regime on the entire history of the transition variable (i.e., its time series process) and not just on a single value (probability) as in the standard Markov switching model.

We will consider smooth transition regression (STR) models, however, the threshold case with abrupt change from one regime to another is embedded as a special case when the adjustment speed goes to infinity. We determine how real exchange rate returns react to oil-market shocks

empirically, in particular, we estimate the adjustment speeds. Negative and positive oil-market shocks can have different effects and also small and large oil-market shocks (in absolute terms) are allowed to influence exchange rates differently. Our model therefore allows us to test Hamilton's $(1996,2003)$ hypothesis that only oil price increases matter. We should note that we do not model the time-series behavior of exchange rates themselves but rather assess only the impact that oil-market shocks have on them, following the two-step methodology of Kilian (2009). 
We estimate a nonlinear model of the form

$$
\Delta f x_{t}=\alpha+\beta_{1}^{\prime} X_{t}+\left(\beta_{2}^{\prime} X_{t}\right) F\left(\tau_{t} ; \gamma, k\right)+\lambda \Delta f x_{t-1}+\eta_{t},
$$

where $\Delta f x_{\mathrm{t}}$ is the change in the log exchange rate, and $F(\cdot)$, the transition function, is generally bounded between 0 and $1, \gamma$ is a positive parameter indicating how fast the transition from one regime to another occurs, $k$ locates where the transition occurs, and $\tau_{t}$ is a covariance-stationary and ergodic transition variable. $X_{t}$ is a vector of regressors that contains in our case just one of the oilmarket shocks, and $\beta_{1}$ and $\beta_{2}$ are associated parameters. We include the lag on the exchange rate as it improves the fit of the model.

The transition variable triggers the smooth transition from one regime to another (Granger and Teräsvirta, 1993; Teräsvirta, 1994, 1998). Generally, the transition function is assumed to be either of the logistic (LSTR) or exponential (ESTR) form. The class of nonlinear models is infinite. But, the choice of LSTR and ESTR models is based on a relatively simple form with only a few parameters to estimate. Also, we rely on the successful application of such models to exchange rate behavior in the literature and on the availability of a complete econometric toolkit for estimation and inference.

In the LSTR model, the transition function is monotonically increasing in the transition variable:

$$
F\left(\tau_{t} ; \gamma, k\right)=\left\{1+\exp \left[-\gamma\left(\tau_{t}-k\right)\right]\right\}^{-1}, \gamma>0 .
$$

The logistic function $F\left(\tau_{t} ; \gamma, k\right)$ is bounded between 0 and 1 as $\tau_{t}$ increases from small (negative) values to large (positive) values. When $\tau_{t}=k$ it has a value of 0.5 . In our applications we set $k=0$ so that our model distinguishes between negative and positive values of $\tau_{\mathrm{t}}$, i.e., we allow regimes to be different for positive and negative values of $\tau_{\mathrm{t}}$. We consider for the transition variable in turn each of the oil-market shocks, denoted $\varepsilon_{i t}$. Therefore, we allow for negative and positive oilmarket shocks to affect exchange rates differently and in addition we allow in each case for the size of the oil-market shock to influence its effect on exchange rate returns. For large values of the transitions speed parameter $\gamma$, the transition of $F\left(\tau_{t} ; \gamma, k\right)$ from 0 to 1 becomes almost instantaneous. Hence, the LSTR model nests a two-regime threshold model with abrupt regime changes as a special case as $\gamma \rightarrow \infty$. On the other hand, when $\gamma=0$ the logistic function equals a constant (0.5) and the LSTR model reduces to a linear model. 
The ESTR model is a non-monotonic alternative that is symmetric around $k$. It allows for different behavior for large and small deviations from the threshold $k$, regardless of the sign of the deviation:

$$
F\left(\tau_{t} ; \gamma, k\right)=1-\exp \left[-\gamma\left(\tau_{t}-k\right)^{2}\right], \quad \gamma>0
$$

The exponential function $F\left(\tau_{t} ; \gamma, k\right) \rightarrow 1$ as $\tau_{t} \rightarrow-\infty$ and also as $\tau_{t} \rightarrow \infty$, and further $F\left(\tau_{t} ; \gamma, k\right)$ $=1$ for $\tau_{t}=k$. Setting $\tau_{t}=\varepsilon_{i t}$ and $k=0$ allows for an inner regime around the point where shocks are zero $\left(\tau_{t}=\varepsilon_{i t}=0\right.$ and $\left.\mathrm{F}(\cdot)=0\right)$ and the adjustment process of exchange rates becomes linear in equation (1). For large shocks, in absolute terms, when $\tau_{t} \rightarrow \pm \infty$, the ESTR function F( $\cdot$ ) $\rightarrow$ 1 and describes an outer regime for which equation (1) becomes in the limit a different linear model. The ESTR process is a generalization of a two-regime threshold model. The adjustment process for positive and negative oil-market shocks is the same in the ESTR model.

The adjustment speed $\gamma$ and location parameter $k$ can be estimated via nonlinear least squares. A problem arises because equation (1) is not identified under the null hypothesis of linearity. Teräsvirta $(1994,1998)$ suggested estimating an auxiliary regression instead:

$$
\Delta f x_{t}=\alpha+\beta_{1}^{\prime} X_{t}+\delta_{0}^{\prime} X_{t} \tau_{t}+\delta_{1}^{\prime} X_{t} \tau_{t}^{2}+\delta_{2}^{\prime} X_{t} \tau_{t}^{3}+\lambda \Delta f x_{t-1}+\eta_{t},
$$

where the null hypothesis of linearity is given by $\delta_{0}^{\prime}=\delta_{1}^{\prime}=\delta_{2}^{\prime}=0$. Testing the LSTR against the ESTR model within equation (3) implies testing $\delta_{2}^{\prime}=0$, because the ESTR model requires that this coefficient is zero. It is important that $\tau_{\mathrm{t}}$ is moment stationary up to a certain order. We consider each of the oil-market shocks in separation to keep the nonlinear model parsimonious.

\subsection{The identification of global oil-market shocks}

Our identification of the structural shocks of the global oil market is based on two alternative structural VAR (SVAR) models: Kilian 2009) and Kilian and Murphy (2014). In Kilian (2009), the global oil market consists of three variables: one supply and two demand variables. The supply variable is a vertical short-run oil supply curve (i.e., flow supply), a demand variable representing aggregate demand for global industrial commodities (i.e., flow demand) and an oil-specific demand variable that reflects the real price of oil (i.e., other demand). The residual demand shock thus captures a whole array of other shocks to oil prices besides flow demand and flow supply shocks. In addition to the fundamental laws of supply and demand, expectations play an important role in setting the price of oil. For example, concerns about future supply shortfalls or rising demand leads to a higher demand for crude oil inventories in the current period, causing the price of oil to rise 
instantaneously. In this way, the change in crude oil inventories above the ground reflects speculative motives in regards to future oil price movements. It also highlights the degree of concerns about future oil supplies, including precautionary motives and strategic oil reserves. The main mechanism underlying these dynamics is the storability of oil, allowing oil traders to take advantage of both rising and falling markets.

To account for the expectations channel of the global oil market explicitly, Kilian and Murphy (2014) added a speculative demand shock (measured by an unexpected change in crude oil inventories) to the SVAR model. In contrast, the oil-market specific demand shocks in Kilian's (2009) model only indirectly identify speculative (or precautionary) oil demand shocks. On the other hand, the flow oil-supply variable reflects any speculative behavior of oil producers, such as pumping less crude oil from below-ground in anticipation of higher future oil prices. It must be noted that due to the inclusion of inventories, the SVAR of Kilian and Murphy (2014) can no longer be identified recursively as in Kilian (2009); instead Kilian and Murphy (2014) use a combination of sign restrictions and bounds on the short-run price elasticities of oil demand and oil supply in order to identify the four structural shocks in the model.

\subsubsection{Identification and estimation of the SVAR model}

\subsubsection{The oil-market SVAR as in Kilian (2009)}

The first step of the analysis is to consider an SVAR:

$$
A_{0} y_{t}=A(L) y_{t-1}+\varepsilon_{t},
$$

where $y_{t}$ includes for $t=1, \ldots, n$ (i) the percentage change in global oil production (prod), (ii) a measure of global economic activity (rea), and (iii) the natural logarithm of the real oil price (rpo); $\varepsilon_{t}$ denotes the vector of serially and mutually uncorrelated structural innovations. The orthogonal structural innovations are estimated by imposing exclusion restrictions on $A_{0}^{-1}$ (see Kilian, 2009)

$$
y_{t}=A_{0}^{-1} A(L) y_{t-1}+e_{t},
$$

with $e_{t}$ a vector of VAR errors such that $e_{t}=A_{0}^{-1} \varepsilon_{t}$. The reduced form VAR errors in equation (5), $e_{t}$, have no economic interpretation as they are correlated with each other. However, the errors in the structural VAR, $\varepsilon_{t}$, do have economic meaning. For our three-variable VAR the identifying structure is as follows: 


$$
e_{t}=\left(\begin{array}{l}
e_{1 t}^{\text {prod }} \\
e_{2 t}^{r e a} \\
e_{3 t}^{r p o}
\end{array}\right)=\left[\begin{array}{ccc}
a_{11} & 0 & 0 \\
a_{21} & a_{22} & 0 \\
a_{31} & a_{32} & a_{33}
\end{array}\right]\left(\begin{array}{l}
\varepsilon_{1 t}^{s} \\
\varepsilon_{2 t}^{d} \\
\varepsilon_{3 t}^{p r e c}
\end{array}\right)
$$

The three structural shocks are attributed as follows: $\varepsilon_{1 t}^{S}$ denotes shocks to the global supply (production) of crude oil that is available above the ground, the "oil supply shock"; $\varepsilon_{2 t}^{d}$ denotes shocks to the global demand for all industrial commodities that are driven by global real economic activity, the "aggregate demand shock;" and $\varepsilon_{3 t}^{\text {prec }}$ denotes an oil-market-specific demand shock, the "precautionary demand shock." The identification of the parameters in $A_{0}^{-1}$ is achieved by imposing a recursive Cholesky ordering as in Kilian (2009, pp. 1059-1060), who explained in detail the rationale for it. The crude oil supply production is assumed not to respond to innovations to the demand for oil within the same month. Global real economic activity does respond to oil supply shocks within the month but responds to shocks that are specific to the oil market with a delay of a month, i.e., it does not respond contemporaneously. This restriction reflects sluggish adjustment of global real economic activity in response to oil price shocks. Last, the real price of oil is allowed to respond to shocks to both oil production and global real economic activity shocks within the same month. This allows for any exogenous changes in crude oil supply or the real economy to be immediately reflected in oil prices. The oil-market-specific demand shock itself can capture shifts in the price of oil that are due to precautionary demand changes that reflect how concerned markets are about the availability of future oil supplies.

For our sample period, standard DF-GLS tests of Elliott et al. (1996) show evidence in favor of unit roots for the global real economic activity variable and for the log of the real oil price, but these two variables are cointegrated (see Section 3.5.1). On the other hand, the percentage change in the oil supply is stationary in levels. Our oil-market VAR specification therefore fits the cases illustrated by Sims et al. (1990). Sims et al. (1990) showed that the estimated coefficients of the VAR model in levels are consistent and asymptotically normally distributed when unit roots and cointegration are present in the data. Put differently, it is not essential to impose cointegration to achieve consistency of the estimates. ${ }^{5}$

\footnotetext{
${ }^{5}$ Moreover, Hamilton (1994, pp. 651-653) cautioned against imposing invalid cointegration restrictions. Also, we note that it is incorrect to use first-differences of variables (that have unit roots) in a VAR when cointegration is present because then missing error-correction terms create omitted variables bias.
} 


\subsubsection{The oil-market SVAR as in Kilian and Murphy (2014)}

The vector $y_{t}$ in equations (4) and (5) is expanded to include now four variables: global oil inventory changes in levels (inv) are added. The orthogonal structural innovations are again estimated from the reduced form estimates. As the oil inventory data tend to show seasonal swings, the reduced-form VAR is estimated using seasonal dummies. Furthermore, as shown below in Section 3.5.1, three of the four variables in this model have unit root behavior and in addition exhibit a cointegrating relationship. Therefore, a VAR in levels is appropriate for this expanded model as well. The structural shocks $\varepsilon_{1 t}^{S}$ and $\varepsilon_{1 t}^{d}$ have the same interpretation as before; $\varepsilon_{3 t}^{i d i}$ refers to all other (residual) oil-market specific idiosyncratic demand shocks, labelled "idiosyncratic shock" that are not important determinants of the real price of oil; and $\varepsilon_{4 t}^{i n v}$ is a shock due to unexpected changes in above-ground oil inventories that capture speculative motives related to concerns over future oil demand and supply, an "inventory shock" or "speculative oil demand shock".

For identification, sign restrictions are imposed on the expanded $A_{0}^{-1}$ matrix:

$$
e_{t}=\left(\begin{array}{c}
e_{1 t}^{p r o d} \\
e_{2 t}^{r e a} \\
e_{3 t}^{r p o} \\
e_{4 t}^{i n v}
\end{array}\right)=\left[\begin{array}{cccc}
- & + & \text { none } & + \\
- & + & \text { none } & - \\
+ & + & \text { none } & + \\
\text { none none } & \text { none } & +
\end{array}\right]\left(\begin{array}{c}
\varepsilon_{1 t}^{s} \\
\varepsilon_{2 t}^{d} \\
\varepsilon_{3 t}^{i d i} \\
\varepsilon_{4 t}^{i n v}
\end{array}\right)
$$

These sign restrictions are imposed only on the impact of responses. Justifications are explained by Kilian and Murphy (2014). These static sign restrictions are too weak to be informative for identification of the shocks. Additional restrictions are needed: a joint set of dynamic sign restrictions is imposed so that a negative flow supply shock leads to a dynamic response of the real price of oil that is constrained to be positive for at least 12 months. In addition, following Kilian and Murphy (2014), we restrict the impact price elasticity of oil supply to fall within a bound of $[0,0.025]$ primarily because models identified purely based on sign restrictions produce values of this elasticity that are too large to be economically meaningful. Finally, contrary to the existing literature, Kilian and Murphy (2014) suggested using the price elasticity for oil demand "in use" (instead of the price elasticity for oil demand "in production"), because crude oil used (demanded for consumption) in our model could come from flow production and from crude oil in storage. Given that the price elasticity of oil demand in use is weakly negative on impact, we impose -0.8 $\leq$ "price elasticity of oil demand in use" $\leq 0$ for the initial effect. 
Although there are several approaches for estimating sign-identified VAR models, the Bayesian methods are the most common approach. Typically, researchers assume a standard Gaussian-inverse Wishart prior distribution for the reduced-form VAR parameters and a Haar distribution for the rotation matrix, used to construct the structural impact multiplier matrix for the impulse responses. The posterior distribution of the structural impulse responses is derived by applying the identification criteria to each draw of the parameters and rotation matrix from those prior distributions. We will repeat this procedure for five million draws and discard structural models that imply impulse responses not obeying the identifying restrictions.

\subsection{Specification of the Step Two Regression}

After having estimated the oil-market shocks, the next step is to include them, one at a time, in equation (3) in order to test the null hypothesis of linearity for the effects of the oil-market shocks on exchange rate returns for each of the six countries. By construction, the shocks estimated in the two alternative oil-market SVARs are orthogonal to other variables (in regards to (6') see Kilian and Murphy, 2014, p. 463). The extent to which these shocks are orthogonal to exchange rate returns in the second stage regression depends partly on how well the SVAR in the first stage is specified. In the Kilian and Murphy (2014) model, the supply, demand, and speculative shocks are explicitly identified, whereas in the model of Kilian (2009) the speculative shock is only implicitly identified. However, for the second stage regression estimates to be consistent it is only required that the shocks are each a predetermined variable in regards to unexpected changes in exchange rate returns. In other words, pre-determinedness means that there is no feedback from excess stock returns to the oil-market shocks within the same month. This is a commonly used assumption when analyzing the effects of oil-market shocks on financial and macroeconomic variables (e.g., Kilian, 2009). Hence, exchange rate returns are allowed to respond contemporaneously to each one of the oil-market shocks but, on the other hand, shocks to exchange rate returns do not affect oil supply (production), global real economic activity, the speculative oil demand, nor real oil prices within the month and there is a delay of one month or more, if there is any effect at all.

A further potential complication arises because the oil-market shocks are generated regressors when used in the second stage regressions involving exchange rate returns. Generally, this does not cause problems for coefficient estimates themselves but the estimates of their standard errors are not consistent because the sampling variation in the generated regressors is ignored 
(Wooldrigde, 2010). Although, the exact implications depend on the specific model and assumptions. We do not include lags on the generated regressors (the oil-market shocks). ${ }^{6}$ Our model hence fits the Model 4 in Pagan (1984, p. 232) with $\gamma=0$. Pagan (p. 233) showed that for $\gamma$ $=0$ the second stage ordinary least squares estimators are efficient and produce consistent estimates of coefficients and standard errors. Murphy and Topel (1985) extended these results to models that are nonlinear. Hence, and estimation and inference can proceed as usual in our second stage regressions.

Teräsvirta (1998, p. 526) suggested using for the nonlinear specification the transition variable that yields the smallest $p$-value for the null hypothesis test when comparing a transition variable with and without a time lag and with different lag lengths. We analyze the impact of oil-market shocks $i$ on exchange rate returns so that $X_{t}=\varepsilon_{i t}$ in equation (1) and we also choose the $i^{\text {th }}$ oilmarket shock $\varepsilon_{i t}$ as the transition variable. Further, for all oil-market shocks and all countries, the un-lagged transition variable is chosen with Teräsvirta's approach, which is consistent with the foreign exchange market being an efficient market. Hence, equation (3) reduces to:

$$
\Delta f x_{t}=\alpha+\beta_{1} \varepsilon_{i t}+\delta_{0} \varepsilon_{i t}^{2}+\delta_{1} \varepsilon_{i t}^{3}+\delta_{2} \varepsilon_{i t}^{4}+\lambda \Delta f x_{t-1}+\eta_{t}
$$

For the LSTR model, the null hypothesis of linearity that $\delta_{0}=\delta_{1}=\delta_{2}=0$ in equation (7) is tested with a Wald test. The test for $\delta_{2}=0$ is a $t$-test of the LSTR versus the ESTR model. In order to test linearity for the ESTR model, we impose $\delta_{2}=0$ and test the null hypothesis of linearity that $\delta_{0}=\delta_{1}=0$. On the other hand, the linear model itself can be tested by imposing linearity in equation (7) with $\delta_{0}=\delta_{1}=\delta_{2}=0$ and then test the null hypothesis that $\beta_{1}=0$. This is a test of the hypothesis that the oil-market shock in question has no (linear) effect on exchange rate returns.

With $X_{t}=\tau_{t}=\varepsilon_{i t}$ the LSTR model for oil-market shocks takes the following form: ${ }^{7}$

$$
\Delta f x_{t}=\alpha+\beta_{1} \varepsilon_{i t}+\beta_{2} \varepsilon_{i t}\left\{1+\exp \left[-\gamma\left(\varepsilon_{i t}\right)\right]\right\}^{-1}+\lambda \Delta f x_{t-1}+\eta_{t} .
$$

The linear model is given by

$$
\Delta f x_{t}=\alpha+\beta_{1} \varepsilon_{i t}+\lambda \Delta f x_{t-1}+\eta_{t} .
$$

An identifying assumption for the LSTR model is that the adjustment speed $\gamma>0$.

\footnotetext{
${ }^{6}$ This is consistent with efficient markets theory that implies that exchange rates should react to news without delay.

${ }^{7}$ In the empirical specification, we considered additional lags on $\Delta f x_{t}$, however these did not improve the model fit.
} 


\subsection{Data}

The monthly data employed are the world crude oil production (supply), the global real economic activity index from Kilian (2009), real US refiners' imported crude oil prices, aboveground crude oil inventories, and the exchange rates. ${ }^{8}$ The sample period for the oil-market model start in January 1974. The US refiners' acquisition cost of crude oil is deflated by the US CPI to calculate real oil prices in dollars per barrel. Nominal exchange rates are converted to real exchange rates using the appropriate consumer price index (CPI) ratio between the two countries. We classify Brazil, Canada, Mexico, Norway, Russia and the UK as net oil exporting countries. The sample period used for estimating the effects of oil-market shocks on exchange rate returns of individual countries starts at the earliest with February 1976, due to observations used up for lag construction in the SVAR. For Canada, Norway, and the UK models are estimated over the period from February 1976 to February 2014. For the other countries, the estimation period starts from the date when crawling-peg exchange rates were abandoned in favor of floating exchange rates (allowing for a one-period lag to calculate returns): February 1995 for Brazil, February 1995 for Mexico, and October 1998 for Russia. Brazil put in place the Plano Real in 1994 that introduced a new currency, and monetary and fiscal policy measures to stabilize the economy. Mexico adopted floating exchange rates from 19 December 2014 and Russia after the Russian financial crisis from 2 September 1998 onwards.

For all countries, the monthly real ex-post returns on exchange rates (foreign exchange returns) are constructed using $\Delta f x_{\mathrm{t}}=100 \ln \left(f x_{t} / f x_{t-1}\right)$, where $f x_{t}$ is the real exchange rate in period $t$. Figure 1 depicts real exchange rates for each country. The share of the oil rent in GDP gives an indication of the importance of oil to the economy of each country. In Figure 2, oil rents are the difference between the value of crude oil production at world prices and total costs of production. We restrict our analysis to countries (and sample periods) with essentially independently floating exchange rates, as defined by the IMF $(2004,2014)$, that are among the top twenty crude oil exporters (Europe's Energy Portal, 2016). Four of these countries are classified by the $\operatorname{IMF}(2014,2004)$ as countries with freely floating exchange rates: Canada, Mexico, Norway and the UK. The US dollar falls into this category of freely floating currencies as well, although it is not a net crude-oil exporter, but we use US-dollar based exchange rates. Brazil's real is classified as an independently floating exchange rate and we include it in our analysis. The Russian ruble is a more or less

\footnotetext{
${ }^{8}$ Details for data sources are given in the Appendix.
} 
managed floating currency with no explicitly stated anchor (IMF, 2004), however, currency management arrangements changed over time and it is debatable how freely the ruble has been floating (see Central Bank of the Russian Federation, 2014). Nevertheless, we include Russia in our sample, noting that it ends before the Russian financial crisis in the second half of 2014 that lead to large interventions by the Russian Central Bank to support a collapsing ruble.

Several other countries among the top twenty oil exporters have had fixed-peg currency arrangements, mostly to the US dollar (if not de jure then de facto): Kuwait, Libya, Oman, Qatar, Saudi Arabia and the United Arab Emirates (IMF, 2004, 2014). The remaining countries among the top twenty managed and stabilized their currencies to various degrees (Algeria, Iran, Iraq, Nigeria, Kazakhstan and Venezuela), with some countries anchoring their currencies to the US dollar (Angola and Azerbaijan). In addition, several of these countries experienced political and civil unrest, sanctions on oil exports, and war, affecting foreign exchange market arrangements.

\subsection{The impact of oil-market shocks on exchange rates: results}

\subsubsection{Unit roots and cointegration}

As a first step, we test the variables, as specified for the SVAR in equation (4), for unit roots with the DF-GLS test, using Akaike's information criterion for lag-length selection and a constant term in the test regression. The percentage change in the oil supply is well described by a covariance-stationary process for our sample. The DF-GLS statistic takes on a value of -2.37 , so that the null hypothesis of a unit root is comfortably rejected at the $5 \%$ level. On the other hand, the percentage deviation from trend of the global economic activity index and the log of the real oil price show each unit root behavior. The DF-GLS test takes on values of -0.80 and -1.05 (or 1.59 if additionally a time trend is included in the test regression for oil prices) for these two variables, respectively. The change in inventories also shows unit root behavior (the test statistic has a value of -1.27). Therefore, the null hypotheses of a unit root cannot be rejected, even at the $10 \%$ level, for all three variables. However, the three variables are cointegrated, based on Johansen's (1995) trace and maximum eigenvalue tests with $p$-values for the null hypothesis of no cointegration of 0.0005 and 0.01 , respectively, and $p$-values for the hypothesis of at most one (two) cointegrating vector of $0.01(0.11)$ for both tests. This means that the evidence suggests the presence of two cointegrating vectors among the three variables. There is also cointegration among the global economic activity index and the real price of oil: Johansen's (1995) trace and 
maximum eigenvalue tests produce $p$-values for the null hypothesis of no cointegration of 0.001 and 0.002 , respectively, and $p$-values for the hypothesis of at most one cointegrating vector of 0.07 for both tests. Engle-Granger tests confirm these findings. Our SVAR specifications hence fit the framework of Sims et al. (1990), as discussed in Section 3.2.1.

In order to avoid spurious regressions due to the presence of unit roots in the second stage regression with exchange rates, we applied the DF-GLS test to real and nominal exchange rate returns. We found empirical support of covariance stationarity for both exchange rate returns for all countries. The null hypothesis of a unit root was rejected. In addition, we tested all oil shocks individually and these time-series process also turned out to be stationary. ${ }^{9}$

\subsubsection{Results for real exchange rate returns: Kilian's (2009) oil-market shocks}

Table 1 reports the results for the various linearity tests for equation (7) with real exchange rate returns and the three structural oil-market shocks defined in equation (6) based on an SVAR with 24 lags. All of the characteristic roots of the VAR are within the unit circle and the residuals are white noise. Entries in bold mark significance at the 5\% level. The third column of Table 1 reports $p$-values for an oil supply shock for the various tests of equation (7). We cannot reject the linear model with $p$-values of 0.11 in two cases and 0.20 or lager in all other cases, except for Russia. That is we cannot reject the hypotheses that $\delta_{0}=\delta_{1}=\delta_{2}=0$ for the LSTR and $\delta_{0}=\delta_{1}=0$ for the ESTR model (with $\delta_{2}=0$ imposed) in those instances. Next, we test for all countries whether oil supply shocks affect exchange rate returns in the linear model where $\delta_{0}=\delta_{1}=\delta_{2}=0$ is imposed in equation (7) and the null hypothesis that $\beta_{1}=0$ is tested. We do not find a significant linear influence of oil supply shocks on exchange returns, as $p$-values are 0.26 or larger. On the other hand, the LSTR model is supported for oil supply shocks for Russia. The hypothesis that $\delta_{0}=\delta_{1}=\delta_{2}=0$ is strongly rejected for Russia with a $p$-values of 0.002 . Also, the $t$-test for the hypothesis that $\delta_{2}=0$ is rejected with a $p$-value of 0.006 , showing that the ESTR model with symmetric adjustment is rejected in favor of the LSTR model with asymmetric adjustment. We note that the linear model would indicate for Russia that an oil supply shock has no impact on exchange rate returns due to a $p$-value of 0.26 .

The fourth column of Table 1 reports $p$-values for global aggregate demand shocks for the tests of equation (7). We cannot reject the linear model for Brazil, Russia and the UK. For these three

\footnotetext{
${ }^{9}$ Detailed results are available from the authors on request.
} 
countries, we test next whether aggregate demand shocks affect exchange rate returns in the linear model $\left(\delta_{0}=\delta_{1}=\delta_{2}=0\right)$ in equation (7). We find a significant linear influence of aggregate demand shocks only for the UK because we reject the null hypothesis that $\beta_{1}=0$ with a $p$-value of 0.03 . The $p$-values for Brazil and Russia are 0.35 and 0.62 respectively. On the other hand, the LSTR model is supported for aggregate demand shocks for Canada, Mexico and Norway. The hypothesis that $\delta_{0}=\delta_{1}=\delta_{2}=0$ is strongly rejected for these countries with $p$-values of 0.007 or less. Also, the $t$-tests for the hypothesis that $\delta_{2}=0$ are rejected for Canada, Mexico and Norway with $p$ values of 0.03 or larger, thus showing support for the LSTR model. It is interesting to note that the linear model would indicate instead incorrectly for Mexico and Norway that aggregate demand shocks have no impact on exchange rate returns because the $p$-values are 0.82 and 0.14 , respectively.

The last column in Table 1 presents results for oil-market-specific demand shocks. At the 5\% level of significance there is no support for the LSTR or the ESTR models for all six countries with $p$-values of 0.24 or larger, except for Norway where we get $p$-values of 0.09 and 0.08 . Hence, linearity cannot be rejected for all countries at the conventional 5\% level of significance. We test next whether oil-specific demand shocks have a significant linear influence on exchange rate returns. The hypothesis $\beta_{1}=0$ cannot be rejected for Brazil, Mexico and the UK with $p$-values of $0.20,0.10$ and 0.15 , respectively. This means that oil-specific demand shocks have no statistically significant effects on exchange returns for these countries. On the other hand, the hypothesis that $\beta_{1}=0$ is strongly rejected for Canada, Norway and Russia with $p$-values of 0.004 or smaller. Hence, oil-specific demand shocks significantly affect exchange returns for Canada, Norway and Russia, but only linearly.

Table 2 reports the regression results for the nonlinear models chosen based on the analysis in Table 1. The identifying assumption for the LSTR model that the adjustment speed $\gamma>0$ holds for all LSTR results with global aggregate demand shocks for Canada, Mexico and Norway, and with oil supply shocks for Russia. The nonlinear impact on the exchange rate returns, measured by $\beta_{2}$, is negative for Canada, Norway and Russia, meaning that a positive shock leads to an appreciation of their currencies relative to the US dollar. However, for Mexico the coefficient estimate for $\beta_{2}$ is positive, albeit not statistically significant at the $5 \%$ level, implying a depreciation of the Mexican peso. A global aggregate demand shock affects the currencies of oil exporting countries through both the change in the price of oil and the change in the demand for other goods than oil 
that they export. An increase in global aggregate demand normally leads to an appreciation of the oil exporter's currency, thus generating a Dutch disease effect. But, depending on the share of oil exports in total exports, central banks may have incentives to actively counter appreciation pressures by accumulating foreign exchange reserves, thus lessening or reversing appreciation pressures (Buetzer et al., 2012).

The $\beta_{2}$-coefficient estimate in Table 2 is clearly statistically significantly different from zero for Canada ( $p=0.001)$ and is a borderline case for Mexico and Russia ( $p=0.07$ in both cases), though the estimate of the adjustment speed $\gamma$ is statistically significantly different from zero for both countries ( $p=0.02$ and 0.01$)$, as it is for Canada ( $p=0.001)$. On the other hand, the $\beta_{2}$ estimate is not significantly different from zero for Norway $(p=0.29)$. In addition, the coefficient estimate for $\gamma$ for Norway is not significantly different from zero either $(p=0.47)$, which indicates that an LSTR model does not describe adequately the nonlinear adjustment process for global aggregate demand shocks for Norway. However, the results for Norway in Table 1 showed that the linear model is not adequate either in the case of global aggregate demand shocks. It would seem that a larger SVAR model of the Norwegian economy is needed in order to capture the dynamic response of exchange rate returns in this case, which is beyond the scope of our paper.

Table 3 reports the results for the shocks for which the linear model is supported by the data: oil-market-specific shocks for Canada, Norway and Russia, and global aggregate demand shocks for the UK. All of these shocks show a negative and statistically highly significant estimate for $\beta_{1}$ so that a positive shock leads to an appreciation of the currencies of these countries relative to the US dollar, as one would expect.

\subsubsection{Results for real exchange rate returns: Kilian and Murphy's (2014) oil-market shocks}

We estimate the four structural oil-market shocks from the SVAR, using the identification structure as given in equation (6'). The SVAR was again estimated with 24 lags. We find in our sample 91 admissible structural VAR models that obey the identifying assumptions. We estimated a value of -0.2539 for the posterior median of the price elasticity of oil demand in use. We follow 
Kilian and Murphy (2014) and choose among the admissible SVAR models the one that has an elasticity of oil demand in use closest to this value. ${ }^{10}$

The third column of Table 4 reports $p$-values for an oil supply shock for the various linearity tests of equation (7) for real exchange rate returns. We cannot reject the linear model for all countries because the $p$-values are larger than 0.05 , with no value below 0.10 , except for the UK for the LSTR model with a value of 0.09. Next, we test whether oil supply shocks affect exchange rate returns in the linear model where $\delta_{0}=\delta_{1}=\delta_{2}=0$ is imposed and the null hypothesis is $\beta_{1}=0$. We do not find a significant influence of oil supply shocks on exchange returns either, as all $p$ values are 0.13 or larger. These results indicate that an oil supply shock has no impact on exchange rate returns for any country for the oil supply shocks derived from Kilian and Murphy's (2014) SVAR.

The fourth column of Table 4 reports $p$-values for global aggregate demand shocks. We cannot reject the linear model for Brazil and the UK. For these two countries, we test next whether aggregate demand shocks affect exchange rate returns in the linear. We find a significant linear influence at the 5\% level for aggregate demand shocks only for the UK because we reject the null hypothesis that $\beta_{1}=0$ with a $p$-value of 0.01 , whereas for Brazil the $p$-value is 0.09 . On the other hand, the LSTR model is supported for aggregate demand shocks for Canada, Mexico, Norway and Russia. The hypothesis that $\delta_{0}=\delta_{1}=\delta_{2}=0$ is strongly rejected for these countries with $p$-values of 0.02 or less. Also, the $t$-tests for the hypothesis that $\delta_{2}=0$ lead to rejections of the ESTR model for these countries with $p$-values of 0.04 or smaller, showing support for the LSTR model. The linear model would indicate instead incorrectly for Mexico and Russia that aggregate demand shocks have no impact on exchange rate returns because the $p$-values are 0.32 and 0.23.

The last two columns in Table 4 present results for idiosyncratic oil-market-specific demand shocks and oil inventory (speculative oil demand) shocks. At the 5\% level of significance there is no support for the LSTR or the ESTR models for all six countries with $p$-values of 0.12 or larger, except for Mexico where we get a $p$-value of 0.09 for the ESTR model for idiosyncratic shocks ("all other shocks"). Hence, linearity cannot be rejected for all countries at the conventional 5\% level. Next, we test whether idiosyncratic and oil inventory shocks have a significant linear influence on real exchange rate returns. In all cases, the hypothesis $\beta_{1}=0$ cannot be rejected at

\footnotetext{
${ }^{10}$ Alternatively, one could choose the most likely (or modal) model that maximizes the joint posterior density of a set of admissible models with the $100(1-\alpha) \%$ highest posterior density. See Inoue and Kilian $(2013,2017)$.
} 
the 5\% level of significance. This means that idiosyncratic and oil inventory shocks have no statistically significant effects on real exchange returns for these countries.

Table 5 lists the results for the nonlinear models chosen based on the analysis in Table 4, which is the LSTR model with global aggregate demand shocks in all cases. The identifying assumption that $\gamma>0$ holds for all countries: Canada, Mexico, Norway and Russia. The nonlinear impact on the exchange rate returns, measured by $\beta_{2}$, is negative and statistically significantly different from zero for Canada, meaning that a positive shock leads to an appreciation of its currency relative to the US dollar. However, for Mexico, Norway and Russia the coefficient estimates for $\beta_{2}$ are positive, but their effects are not statistically significant at the $5 \%$ level, except for Norway.

The estimates of the adjustment speed $\gamma$ in Table 5 are not statistically significantly different from zero at the 5\% significance level for all four countries. Although, the coefficient estimate for $\gamma$ for Canada is a borderline case $(p=0.06)$ in terms of significance, which indicates that an LSTR model may describe adequately the nonlinear adjustment process for Canada. On the other hand, for Mexico, Norway and Russia it would seem that a larger SVAR model of their economies is needed in order to capture the dynamic responses.

Table 6 lists the results for the global aggregate demand shock for the UK for which the linear model is supported by the data. A negative and statistically significant estimate for $\beta_{1}$ means that a positive shock leads to an appreciation of the British pound relative to the US dollar, as expected.

\subsubsection{Results for nominal exchange rate returns: Kilian and Murphy's (2014) oil-market} shocks

In this section, we use nominal exchange rates instead of real exchange rates for calculating exchange rate returns. This specification is motivated by the wealth channel that emphasizes the effects on nominal exchange rates, whereas the terms of trade channel mainly works through relative prices so that real exchange rates instead are more relevant (Beckmann and Czudaj, 2013). The results for the linearity tests with nominal exchange rate returns for equation (7) are reported in Table 7.

For oil supply shocks, the test statistics support the same model specifications as in the model with real exchange rate returns in Table 4 in terms of LSTR, ESTR or linear specifications, even though individual $p$-values differ somewhat. For global aggregate demand shocks, qualitative results are again unaffected when real exchange rate returns are replaced with nominal ones, except 
for Brazil, Russia and the UK. The tests now support a linear model for Brazil and the ESTR model for the UK, whereas there are no significant effects at all for Russia. For idiosyncratic oilmarket shocks the qualitative results align again with the results for real returns in Table 4, except for Norway, where the linear model is supported. For speculative oil-inventory shocks, the results for the effects are unchanged in comparison with Table 4. Estimation details for the statistically significant adjustment processes are reported in Tables 8 and 9. The qualitative results are broadly consistent with those for real exchange rates in Tables 5 and 6 for Canada, Mexico and Norway. All shocks concerned are global aggregate demand shocks, except for Norway with linear idiosyncratic shocks affecting nominal exchange rates in Table 9.

\subsubsection{Overall assessment of the empirical results}

Generally, we find that the results obtained with the oil-market shocks from the SVAR of Kilian (2009) are broadly speaking similar to those derived from the SVAR of Kilian and Murphy (2014). The only exceptions are the results for the oil-market specific shocks of Kilian (2009) as compared to the inventory shocks and idiosyncratic shocks of Kilian and Murphy (2014). The speculative demand shocks are not explicitly identified in Kilian's (2009) model and are defined as residual shocks in the oil market that are not due to either oil production (supply) or global aggregate demand (demand for oil in use). The advantage of Kilian and Murphy's (2014) SVAR is that it explicitly identifies shocks due to speculative behavior in the crude oil market and separates them form residual idiosyncratic shocks that are not important systematic drivers of oil prices. We therefore rely on the model of Kilian and Murphy (2014) when assessing the effects of oil-market shocks on the exchange rates of major oil exporting countries.

We find that oil supply shocks are not driving the exchange rate movements of oil exporting countries, whether one looks at real or nominal exchange rates. This result is in line with the findings of Kilian (2009) and Kilian and Vigfusson (2011a, 2011b) for US real GDP, and Basher et al. (2016) using a Markov-switching model. Real and nominal exchange rates are instead driven by shocks to the global aggregate demand of crude oil in use. Speculation in the crude oil market does not exert any systematic influence on the movement of exchange rates of the oil exporters relative to the US dollar, with the possible exception of the nominal exchange rate for Norway. Furthermore, the idiosyncratic shocks are indeed empirically unimportant in regards to exchange rates. 
Global aggregate demand shocks, which are shocks to the global demand for industrial commodities, relate in a nonlinear way to real exchange rates for Canada, Mexico, Norway, and Russia, and in a linear way for the UK. The relationship is also nonlinear for nominal exchange rate effects for Canada, Mexico, Norway, and the UK, and linear for Brazil. That real and nominal exchange rates react differently to aggregate demand shocks is consistent with the theories discussed earlier for the channels through which oil-market shocks affect exchange rates. Furthermore, we note that a linear analysis would have concluded incorrectly that global aggregate demand shocks have no statistically significant effects on exchange rate returns for several cases.

\section{Conclusions and implications}

We examined the response of monthly exchange rate returns to oil price shocks for six major oil exporting countries with (more or less) flexible exchange rate regimes. Other major oil exporting countries have had instead regimes of pegged or managed exchange rates. We used two alternative structural VAR models: Kilian's (2009) model with three oil-market shocks and Kilian and Murphy's (2014) model with four oil-market shocks. In contrast to the previous literature on oil-market shocks and exchange rates, we considered flexible nonlinear forms for adjustments to shocks, besides linear adjustment. We specified logistic (asymmetric) and, alternatively, exponential (symmetric) nonlinear adjustment processes of the form that have been successfully employed before in the literature on empirical modelling of the dynamics of exchange rates themselves. This methodology allowed us to estimate quite parsimoniously a flexible reaction function for exchange rate returns to each of the oil-market shocks.

Our findings are that the explicit identification of speculative oil-market shocks proposed by Kilian and Murphy (2014) is important for properly assessing the effects of shocks other than oil supply and global aggregate demand shocks. Overall global oil supply shocks have no statistically significant effects on real and nominal exchange rate returns of oil exporting countries, for linear as well as nonlinear specifications. Nominal and real exchange rates are instead driven by crude oil demand "in use" that depends on global business cycle fluctuations and the demand for industrial commodities. Our result are relevant for the debate on the role of oil price shocks, with Hamilton (2003, 2011, and 2016), among others, emphasizing oil supply shocks as the main driver on one side of the debate, and Kilian (2009), Kilian et al. (2009), Kilian and Vigfusson (2011a, 
2011b), and Kilian and Murphy (2014) emphasizing global aggregate demand and speculative crude oil price shocks on the other side.

Our study also showed that shocks directly originating in the oil market, that is oil supply and speculative oil demand shocks, have no asymmetric effects on real and nominal exchange rate returns. Instead, the effects are either linear or symmetrically nonlinear, if they are significant at all. This result is different from the results reported by Basher et al. (2016) for oil-market specific demand shocks derived in Kilian's (2009) set-up: all oil exporters' real exchange rates are statistically significantly affected in at least one regime in their nonlinear Markov models, looking at the preferred models in their Tables 5 and 6 based on regime classification measure values.

Compared to the other three shocks, our results are different for global real economic activity shocks measured with the index of the global production of industrial commodities. We should point out that, unlike other available monthly measures of output, this index includes emerging economies such as China and India (Kilian and Zhou, 2017). We found empirical support for nonlinear asymmetric effects of aggregate demand shocks.

Our findings imply for future research that a structural vector autoregressive model with alternative nonlinear features, such as time-varying parameters, and additional macroeconomic variables would be a worthwhile venue for modelling the dynamics in the case of aggregate demand shocks.

Acknowledgements: The authors thank, without implicating, participants at the EcoMod (in Lisbon) and the SETA/NZESG (in Hamilton) conferences and at seminars at the Free University of Berlin, Norges Bank, and the University of Tübingen for helpful comments on an earlier version.

\section{References}

Amano, R. and van Norden, S. (1998). Oil prices and the rise and fall of the US real exchange rate. Journal of International Money and Finance 17, 299-316.

Atems, B., Kapper, D. and Lam, E. (2015). Do exchange rates respond asymmetrically to shocks in the crude oil market? Energy Economics 49, 227-238.

Backus, D.K. and Crucini, M.J. (2000). Oil prices and the terms of trade. Journal of International Economics 50, 185-213.

Basher, S.A., Haug, A.A. and Sadorsky, P. (2017). The impact of oil-market shocks on stock returns in major oil-exporting countries: A Markov-switching. Available at https://mpra.ub.uni-muenchen.de/81638/1/MPRA_paper_81638.pdf

Basher, S.A., Haug, A.A. and Sadorsky, P. (2016). The impact of oil shocks on exchange rates: A 
Markov-switching. Energy Economics 54, 11-23.

Basher, S.A., Haug, A.A. and Sadorsky, P. (2012). Oil prices, exchange rates and emerging stock markets. Energy Economics 34, 227-240.

Beckmann, J. and Czudaj, R. (2013). Is there a homogenous causality pattern between oil prices and currencies of oil importers and exporters? Energy Economics 40, 665-678.

Bodenstein, M., Erceg, C.J. and Guerrieri, L. (2011). Oil shocks and external adjustment. Journal of International Economics 83, 168-184.

Buetzer, S., Habib, M.M. and Stracca, L. (2012). Global exchange rate configurations: do oil shocks matter? Working Paper Series No 1442, European Central Bank.

Central Bank of the Russian Federation (2014). The history of the Bank of Russia's exchange rate policy. Retrieved 11/02/2016 from http://www.bis.org/publ/bppdf/bispap73u.pdf

Chen, Y.-C. and Rogoff, K. (2003). Commodity currencies. Journal of International Economics 60, 133-160.

Coudert, V., Couharde, C. and Mignon, V. (2011). Does euro or dollar pegging impact the real exchange rate? The case of oil and commodity currencies. World Economy 34, 15571592.

Elliott, G., Rothenberg, T.J. and Stock, J.H. (1996). Efficient tests for an autoregressive unit root. Econometrica 64, 813-836

Europe's Energy Portal (2016). Crude oil exports 2009. Retrieved 15/01/2016 from https://www.energy.eu/stats/energy-oil-exports-net.html.

Fratzscher, M., Schneider, D. and Van Robays, I. (2014). Oil prices, exchange rates and asset prices. Working Paper Series No 1689, European Central Bank.

Golub, S.S. (1983). Oil prices and exchange rates. Economic Journal 93, 576-593.

Granger, C.W.J. and Teräsvirta, T. (1993). Modeling nonlinear economic relationships. Oxford University Press, Oxford, UK.

Hamilton, J.D. (2016). Macroeconomic regimes and regime shifts. NBER Working Paper No. 21863

Hamilton, J.D. (2011). Nonlinearities and the macroeconomic effects of oil prices. Macroeconomic Dynamics 15, 364-378.

Hamilton, J.D. (2003). What is an oil shock? Journal of Econometrics 113, 363-398.

Hamilton, J.D. (1996). This is what happened to the oil price-macroeconomy relationship. Journal of Monetary Economics 38, 215-220.

Hamilton, J.D. (1994). Time series analysis. Princeton University Press, Princeton, NJ.

Herrera, A.M., Lagalo, L.G., and Wada, T. (2016). Asymmetries in the response of economic activity to oil price increases and decreases? Journal of International Money and Finance 50, 108-133.

IMF (2014). Annual report on exchange arrangements and exchange restrictions 2014. Retrieved 11/02/2016 from https://www.imf.org/external/pubs/nft/2014/areaers/ar2014.pdf

IMF (2004). Classification of exchange rate arrangements and monetary policy frameworks. Retrieved 11/02/2016 from https://www.imf.org/external/np/mfd/er/2004/eng/0604.htm

Inoue, A. and Kilian, L. (2013). Inference on impulse response functions in structural VAR models. Journal of Econometrics 177, 1-13.

Inoue, A. and Kilian, L. (2017). Corrigendum to "Inference on impulse response functions in structural VAR models. Retrieved 24/11/2017 from http://www-personal.umich.edu/ 1kilian/ik_corrigendum2017r2.pdf

Johansen, S. (1995). Likelihood-based inference in cointegrated vector autoregressive models. 
Oxford University Press, Oxford, UK.

Kilian, L. (2009). Not all oil price shocks are alike: disentangling demand and supply shocks in the crude oil market. American Economic Review 99, 1053-1069.

Kilian, L. and Lee, T.K. (2014). Quantifying the speculative component in the real price of oil: The role of global oil inventories. Journal of International Money and Finance 42, 71-87.

Kilian, L. and Murphy, D.P. (2014). The role of inventories and speculative trading in the global market for crude oil. Journal of Applied Econometrics 29, 454-478.

Kilian, L., Rebucci, A. and Spatafora, N. (2009). Oil shocks and external balances. Journal of International Economics 77, 181-194.

Kilian, L. and Taylor, M.P. (2003). Why is it so difficult to beat the random walk forecast of exchange rates? Journal of International Economics 60, 85-107.

Kilian, L. and Vigfusson, R.J. (2011a). Are the responses of the US Economy asymmetric in energy price increases and decreases? Quantitative Economics 2, 419-453.

Kilian, L. and Vigfusson, R.J. (2011b). Nonlinearities in the oil price-output relationship. Macroeconomic Dynamics 15, 337-363.

Kilian, L. and Zhou, X. (2017). Modeling fluctuations in the global demand for commodities. CEPR Discussion Papers 12357, C.E.P.R. Discussion Papers.

Krugman, P. (1983). Oil and the dollar. NBER Working Paper No. 0554.

Ma, J. and Wohar, M., Eds. (2014). Recent advances in estimating nonlinear models. With applications in economics and finance. Springer, Berlin.

Mork, K.A. (1989). Oil and the macroeconomy. When prices go up and down: An extension of Hamilton's results. Journal of Political Economy 97, 740-744.

Murphy, K.M. and Topel, R.H. (1985) Estimation and inference in two-step econometric models estimation. Journal of Business and Economic Statistics 3, 88-97.

Pagan, A.R. (1984). Econometric issues in the analysis of regressions with generated regressors. International Economic Review 25, 221-247.

Reboredo, J.C. (2012). Modelling oil price and exchange rate co-movements. Journal of Policy Modeling 34, 419-440.

Sims, C.A., Stock, J.H., and Watson, M.W. (1990). Inference in linear time series models with some unit roots. Econometrica 58, 113-144.

Taylor, M.P., Peel, D.A., and Sarno, L. (2001). Nonlinear mean reversion in real exchange rates: towards a solution to the purchasing power parity puzzles. International Economic Review 42, 1015-1042.

Teräsvirta, T. (1998). Modeling economic relationships with smooth transition regressions. In Ullah, A. and Giles, D., eds., Handbook of applied statistics. Marcel Dekker, New York, 507-552.

Teräsvirta, T. (1994): "Specification, estimation, and evaluation of smooth transition autoregressive models", Journal of the American Statistical Association 89: 208-218.

Teräsvirta, T., Tjøstheim, D. and Granger, C.W.J. (2010). Modelling nonlinear economic time series. Oxford University Press, Oxford.

Wooldridge, J.M. (2010). Econometric analysis of cross section and panel data. Second edition, MIT Press, Cambridge, Mass. 
Figure 1. Monthly real exchange rates
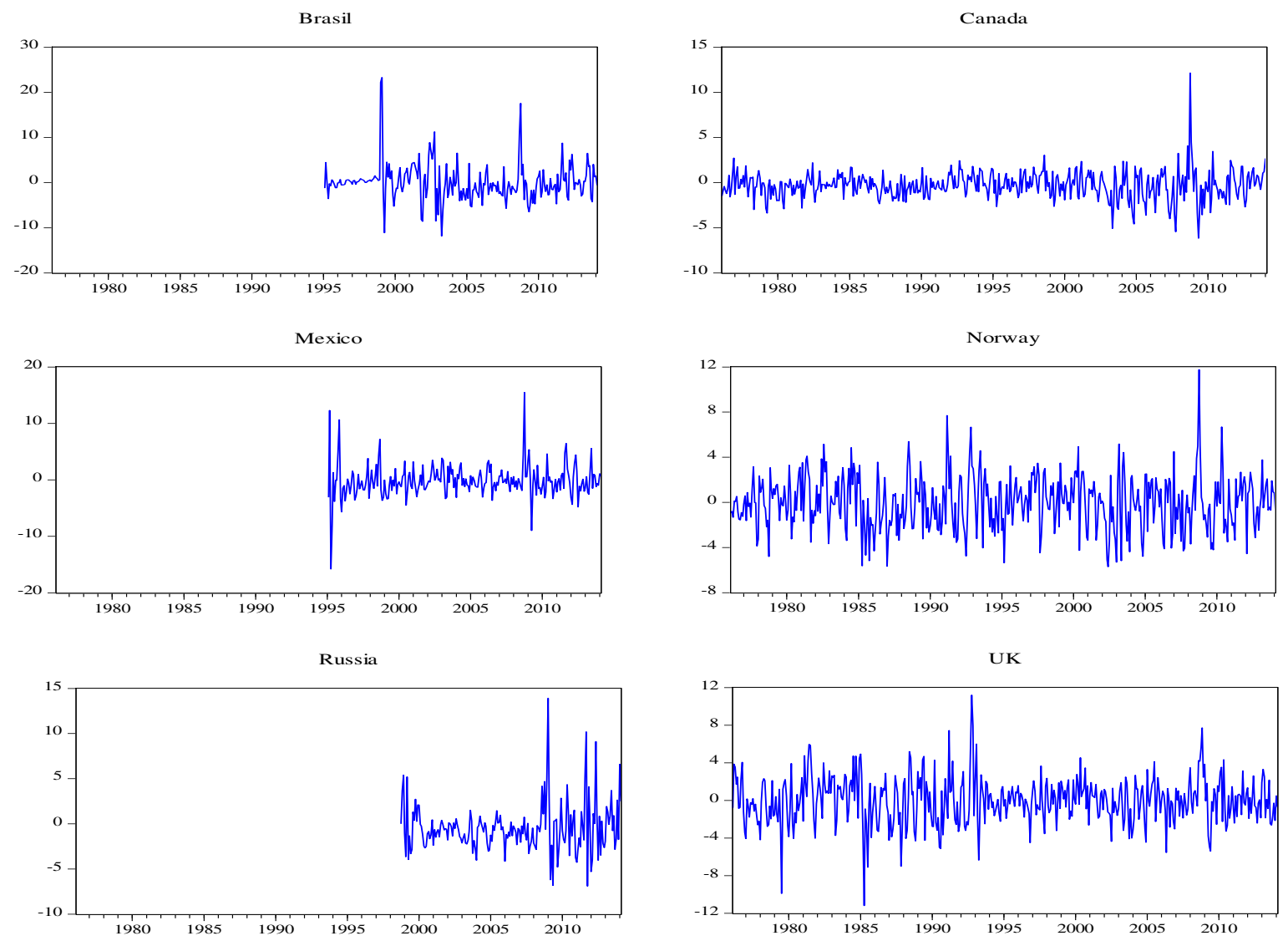

Figure 2. Oil rents (\% of GDP), annual figures

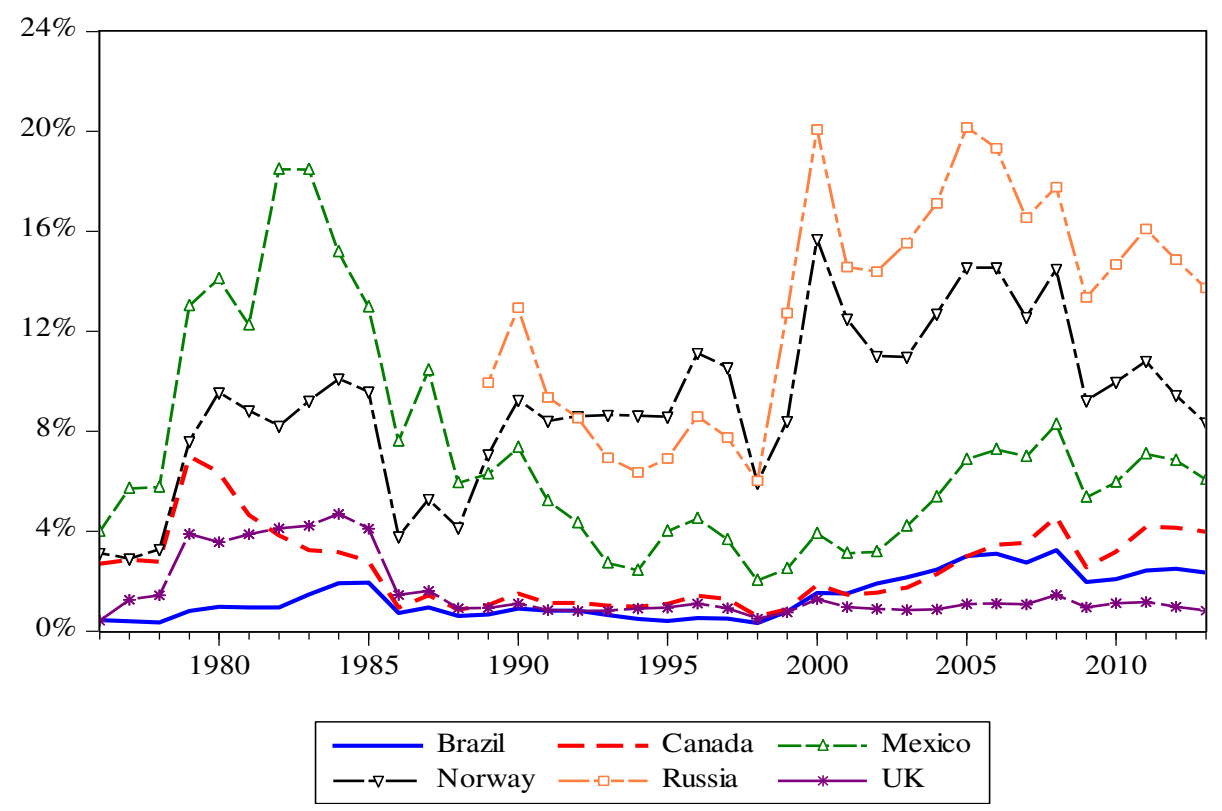


Table 1. $P$-values for tests for equation (7) with real exchange rate returns for the three oil-market shocks from Kilian's (2009) model

\begin{tabular}{|c|c|c|c|c|}
\hline Country & $\begin{array}{l}\text { Model } \\
\text { tested }\end{array}$ & $\begin{array}{l}\text { Oil supply } \\
\text { shock }\end{array}$ & $\begin{array}{l}\text { Aggregate } \\
\text { demand } \\
\text { shock }\end{array}$ & $\begin{array}{l}\text { Oil- } \\
\text { market } \\
\text { specific } \\
\text { shock }\end{array}$ \\
\hline \multirow[t]{3}{*}{ Brazil } & LSTR & 0.11 & 0.15 & 0.54 \\
\hline & ESTR & 0.31 & 0.86 & 0.80 \\
\hline & Linear & 0.85 & 0.35 & 0.20 \\
\hline \multirow[t]{4}{*}{ Canada } & LSTR & 0.73 & 0.0001 & 0.44 \\
\hline & ESTR & 0.71 & 0.0004 & 0.36 \\
\hline & $\delta_{2}=0$ & -- & 0.0001 & -- \\
\hline & Linear & 0.32 & 0.0001 & 0.0001 \\
\hline \multirow[t]{4}{*}{ Mexico } & LSTR & 0.25 & 0.0004 & 0.94 \\
\hline & ESTR & 0.20 & 0.0003 & 0.85 \\
\hline & $\delta_{2}=0$ & -- & 0.009 & -- \\
\hline & Linear & 0.35 & 0.82 & 0.10 \\
\hline \multirow[t]{4}{*}{ Norway } & LSTR & 0.79 & 0.007 & 0.09 \\
\hline & ESTR & 0.60 & 0.02 & 0.08 \\
\hline & $\delta_{2}=0$ & -- & 0.03 & -- \\
\hline & Linear & 0.91 & 0.14 & 0.001 \\
\hline \multirow[t]{4}{*}{ Russia } & LSTR & 0.002 & 0.40 & 0.72 \\
\hline & ESTR & 0.02 & 0.23 & 0.59 \\
\hline & $\delta_{2}=0$ & 0.006 & -- & -- \\
\hline & Linear & 0.26 & 0.62 & 0.004 \\
\hline \multirow[t]{3}{*}{ UK } & LSTR & 0.20 & 0.15 & 0.24 \\
\hline & ESTR & 0.11 & 0.13 & 0.69 \\
\hline & Linear & 0.39 & 0.03 & 0.15 \\
\hline
\end{tabular}

Notes: The tests for the LSTR model are Wald tests for the null hypothesis that $\delta_{0}=\delta_{1}=\delta_{2}=0$. The tests for the ESTR model impose $\delta_{2}=0$ and test the null hypothesis that $\delta_{0}=\delta_{1}=0$. The test of $\delta_{2}=0$ is a t-test of the LSTR versus the ESTR model. The linear model test imposes $\delta_{0}=\delta_{1}=\delta_{2}=0$ and tests that $\beta_{1}=0$, which is a test of whether the oil shock has any linear influence on exchange rate returns. Entries in bold mark significance at the $5 \%$ level. 
Table 2. Estimates for the LSTR model in equation (8) with real exchange rate returns for the three oil-market shocks from Kilian's (2009) model

\begin{tabular}{lllllll}
\hline \multirow{2}{*}{ Country } & Type of shock & \multicolumn{5}{c}{ Coefficient estimates } \\
\cline { 3 - 6 } & & $\alpha$ & $\beta_{1}$ & $\beta_{2}$ & $\gamma$ & $\lambda$ \\
\hline \multirow{2}{*}{ Canada } & Global aggregate & -- & -- & -0.06 & 24.8 & 0.28 \\
& $\begin{array}{l}\text { Demand } \\
\text { Mexico }\end{array}$ & & & $\mathbf{( 0 . 0 0 1 )}$ & $\mathbf{( 0 . 0 0 1 )}$ & $\mathbf{( 0 . 0 0 1 )}$ \\
& $\begin{array}{l}\text { Global aggregate } \\
\text { Demand }\end{array}$ & -- & -- & 0.08 & 8.3 & -- \\
& Norway & & & $(0.07)$ & $\mathbf{( 0 . 0 2 )}$ & \\
& Global aggregate & -- & -- & -0.03 & 1.86 & 0.33 \\
& Demand & & & $(0.29)$ & $(0.47)$ & $\mathbf{( 0 . 0 0 1 )}$ \\
Russia & Oil supply & -- & -- & -0.57 & 93.8 & -- \\
& & & & $(0.07)$ & $\mathbf{( 0 . 0 1 )}$ & \\
\hline
\end{tabular}

Notes: A dashed line indicates that the variable associated with the coefficient was left out of the model because it did not enter the regression statistically significantly at the 5\% level. We report $p$-values in parentheses with those values that are 0.05 or smaller in bold.

Table 3. Estimates for the linear model in equation (9) with real exchange rate returns for the three oil-market shocks from Kilian's (2009) model

\begin{tabular}{|c|c|c|c|c|c|}
\hline \multirow[t]{2}{*}{ Country } & \multirow[t]{2}{*}{ Type of shock } & \multicolumn{4}{|c|}{ Coefficient estimates } \\
\hline & & $\overline{\mathrm{A}}$ & $\beta_{1}$ & $\lambda_{1}$ & $\lambda_{2}$ \\
\hline Canada & $\begin{array}{l}\text { Oil-market- } \\
\text { specific demand }\end{array}$ & $\begin{array}{l}-0.21 \\
(\mathbf{0 . 0 0 2 )}\end{array}$ & $\begin{array}{l}-0.07 \\
(\mathbf{0 . 0 0 1 )}\end{array}$ & $\begin{array}{l}0.28 \\
(\mathbf{0 . 0 0 1 )}\end{array}$ & -- \\
\hline Norway & $\begin{array}{l}\text { Oil-market- } \\
\text { specific demand }\end{array}$ & -- & $\begin{array}{l}-0.06 \\
(\mathbf{0 . 0 0 1 )}\end{array}$ & $\begin{array}{l}0.33 \\
(\mathbf{0 . 0 0 1 )}\end{array}$ & -- \\
\hline Russia & $\begin{array}{l}\text { Oil-market- } \\
\text { specific demand }\end{array}$ & -- & $\begin{array}{l}-0.09 \\
(\mathbf{0 . 0 0 4 )}\end{array}$ & $\begin{array}{l}0.20 \\
(\mathbf{0 . 0 1})\end{array}$ & -- \\
\hline UK & $\begin{array}{l}\text { Global aggregate } \\
\text { Demand }\end{array}$ & -- & $\begin{array}{l}-0.05 \\
(\mathbf{0 . 0 2})\end{array}$ & $\begin{array}{l}0.33 \\
(\mathbf{0 . 0 0 1 )}\end{array}$ & $\begin{array}{l}-010 \\
(\mathbf{0 . 0 3})\end{array}$ \\
\hline
\end{tabular}

Notes: See the notes to Table 2. $\lambda_{1}$ is the coefficient of $\Delta f x_{t-1}$ and $\lambda_{2}$ is the coefficient of $\Delta f x_{t-2}$. 
Table 4. $P$-values for tests for equation (7) with real exchange rate returns for the four oil-market shocks from Kilian and Murphy's (2014) model

\begin{tabular}{|c|c|c|c|c|c|}
\hline Country & $\begin{array}{l}\text { Model } \\
\text { tested }\end{array}$ & $\begin{array}{l}\text { Oil supply } \\
\text { shock }\end{array}$ & $\begin{array}{l}\text { Aggregate } \\
\text { demand } \\
\text { shock }\end{array}$ & $\begin{array}{l}\text { All other } \\
\text { shocks }\end{array}$ & $\begin{array}{l}\text { Oil } \\
\text { inventory } \\
\text { shock }\end{array}$ \\
\hline \multirow[t]{3}{*}{ Brazil } & LSTR & 0.35 & 0.35 & 0.69 & 0.51 \\
\hline & ESTR & 0.22 & 0.21 & 0.57 & 0.45 \\
\hline & Linear & 0.57 & 0.09 & 0.87 & 0.76 \\
\hline \multirow[t]{4}{*}{ Canada } & LSTR & 0.56 & 0.0001 & 0.37 & 0.76 \\
\hline & ESTR & 0.39 & 0.0001 & 0.24 & 0.56 \\
\hline & $\delta_{2}=0$ & -- & 0.0001 & -- & -- \\
\hline & Linear & 0.65 & 0.0001 & 0.32 & 0.60 \\
\hline \multirow[t]{4}{*}{ Mexico } & LSTR & 0.44 & 0.0001 & 0.14 & 0.99 \\
\hline & ESTR & 0.50 & 0.0006 & 0.09 & 0.99 \\
\hline & $\delta_{2}=0$ & -- & 0.001 & -- & -- \\
\hline & Linear & 0.55 & 0.32 & 0.52 & 0.41 \\
\hline \multirow[t]{4}{*}{ Norway } & LSTR & 0.85 & 0.002 & 0.31 & 0.91 \\
\hline & ESTR & 0.97 & 0.02 & 0.98 & 0.78 \\
\hline & $\delta_{2}=0$ & -- & 0.008 & -- & -- \\
\hline & Linear & 0.22 & 0.005 & 0.05 & 0.51 \\
\hline \multirow[t]{4}{*}{ Russia } & LSTR & 0.37 & 0.02 & 0.70 & 0.53 \\
\hline & ESTR & 0.72 & 0.06 & 0.99 & 0.36 \\
\hline & $\delta_{2}=0$ & -- & 0.04 & -- & -- \\
\hline & Linear & 0.75 & 0.23 & 0.09 & 0.37 \\
\hline \multirow[t]{3}{*}{ UK } & LSTR & 0.09 & 0.10 & 0.62 & 0.12 \\
\hline & ESTR & 0.13 & 0.10 & 0.75 & 0.64 \\
\hline & Linear & 0.13 & 0.01 & 0.47 & 0.86 \\
\hline
\end{tabular}

Notes: See Table 1.

Table 5. Estimates for the LSTR model in equation (8) with real exchange rate returns for the four oil-market shocks from Kilian and Murphy's (2014) model

\begin{tabular}{|c|c|c|c|c|c|c|}
\hline \multirow[t]{2}{*}{ Country } & \multirow[t]{2}{*}{ Type of shock } & \multicolumn{5}{|c|}{ Coefficient estimates } \\
\hline & & $\mathrm{A}$ & $\beta_{1}$ & $\beta_{2}$ & $\gamma$ & $\lambda$ \\
\hline Canada & $\begin{array}{l}\text { Global aggregate } \\
\text { Demand }\end{array}$ & -- & -- & $\begin{array}{l}-0.59 \\
(\mathbf{0 . 0 0 0 1})\end{array}$ & $\begin{array}{l}9.68 \\
(0.06)\end{array}$ & $\begin{array}{l}0.28 \\
(\mathbf{0 . 0 0 0 1})\end{array}$ \\
\hline Mexico & $\begin{array}{l}\text { Global aggregate } \\
\text { Demand }\end{array}$ & $\begin{array}{l}0.20 \\
(\mathbf{0 . 0 0 7})\end{array}$ & $\begin{array}{l}-664.9 \\
(0.94)\end{array}$ & $\begin{array}{l}1329.6 \\
(0.95)\end{array}$ & $\begin{array}{l}0.001 \\
(0.95)\end{array}$ & -- \\
\hline Norway & $\begin{array}{l}\text { Global aggregate } \\
\text { Demand }\end{array}$ & -- & -- & $\begin{array}{l}440.2 \\
(\mathbf{0 . 0 0 0 1 )}\end{array}$ & $\begin{array}{l}0.0006 \\
(0.99)\end{array}$ & $\begin{array}{l}0.30 \\
(0.95)\end{array}$ \\
\hline Russia & $\begin{array}{l}\text { Global aggregate } \\
\text { demand }\end{array}$ & $\begin{array}{l}-0.70 \\
(\mathbf{0 . 0 0 5})\end{array}$ & $\begin{array}{l}-0.85 \\
(\mathbf{0 . 0 3})\end{array}$ & $\begin{array}{l}1.41 \\
(0.24)\end{array}$ & $\begin{array}{l}0.68 \\
(0.43)\end{array}$ & $\begin{array}{l}0.09 \\
(\mathbf{0 . 0 2})\end{array}$ \\
\hline
\end{tabular}

Notes: See Table 2. 
Table 6. Estimates for the linear model in equation (9) with real exchange rate returns for the four oil-market shocks from Kilian and Murphy's (2014) model

\begin{tabular}{lllll}
\hline \multirow{2}{*}{ Country } & Type of shock & \multicolumn{3}{c}{ Coefficient estimates } \\
\cline { 3 - 4 } & & $\mathrm{A}$ & $\beta_{1}$ & $\lambda_{1}$ \\
\hline \multirow{3}{*}{ UK } & Global aggregate & -- & -0.32 & 0.30 \\
& Demand & & $\mathbf{( 0 . 0 1 )}$ & $\mathbf{( 0 . 0 0 0 1 )}$ \\
& & & \\
\hline Notes: See Table 3.
\end{tabular}

Notes: See Table 3.

Table 7. P-values for tests for equation (7) with nominal exchange rate returns for the four oil-market shocks from Kilian and Murphy's (2014) model

\begin{tabular}{|c|c|c|c|c|c|}
\hline Country & $\begin{array}{l}\text { Model } \\
\text { tested }\end{array}$ & $\begin{array}{l}\text { Oil supply } \\
\text { shock }\end{array}$ & $\begin{array}{l}\text { Global } \\
\text { aggregate } \\
\text { demand shock }\end{array}$ & $\begin{array}{l}\text { All other } \\
\text { (idiosyncratic) } \\
\text { shocks }\end{array}$ & $\begin{array}{l}\text { Oil } \\
\text { inventory } \\
\text { shock }\end{array}$ \\
\hline \multirow{3}{*}{ Brazil } & LSTR & 0.29 & 0.26 & 0.77 & 0.61 \\
\hline & ESTR & 0.17 & 0.16 & 0.69 & 0.56 \\
\hline & Linear & 0.46 & 0.04 & 0.89 & 0.69 \\
\hline \multirow[t]{4}{*}{ Canada } & LSTR & 0.85 & 0.0001 & 0.42 & 0.51 \\
\hline & ESTR & 0.70 & 0.0001 & 0.24 & 0.31 \\
\hline & $\delta_{2}=0$ & -- & 0.0001 & -- & -- \\
\hline & Linear & 0.60 & 0.0001 & 0.57 & 0.61 \\
\hline \multirow[t]{4}{*}{ Mexico } & LSTR & 0.05 & 0.002 & 0.77 & 0.79 \\
\hline & ESTR & 0.26 & 0.03 & 0.58 & 0.63 \\
\hline & $\delta_{2}=0$ & -- & 0.004 & -- & -- \\
\hline & Linear & 0.24 & 0.12 & 0.13 & 0.80 \\
\hline \multirow[t]{4}{*}{ Norway } & LSTR & 0.72 & 0.0007 & 0.24 & 0.97 \\
\hline & ESTR & 0.75 & 0.008 & 0.84 & 0.96 \\
\hline & $\delta_{2}=0$ & -- & 0.007 & -- & -- \\
\hline & Linear & 0.43 & 0.0008 & 0.04 & 0.35 \\
\hline \multirow[t]{3}{*}{ Russia } & LSTR & 0.96 & 0.60 & 0.76 & 0.09 \\
\hline & ESTR & 0.97 & 0.66 & 0.61 & 0.33 \\
\hline & Linear & 0.21 & 0.22 & 0.34 & 0.17 \\
\hline \multirow[t]{4}{*}{ UK } & LSTR & 0.09 & 0.03 & 0.61 & 0.19 \\
\hline & ESTR & 0.11 & 0.02 & 0.69 & 0.69 \\
\hline & $\delta_{2}=0$ & -- & 0.21 & -- & -- \\
\hline & Linear & 0.30 & 0.008 & 0.69 & 0.77 \\
\hline
\end{tabular}

Notes: See Table 1. 
Table 8. Estimates for the LSTR model in equation (8) with nominal exchange rate returns for the four oil-market shocks from Kilian and Murphy's (2014) model

\begin{tabular}{lllllll}
\hline \multirow{2}{*}{ Country } & Type of shock & \multicolumn{5}{c}{ Coefficient estimates } \\
\cline { 3 - 7 } & & $\alpha$ & $\beta_{1}$ & $\beta_{2}$ & $\gamma$ & $\lambda$ \\
\hline Canada & $\begin{array}{l}\text { Global aggregate } \\
\text { Demand }\end{array}$ & -- & -- & -0.21 & 152.4 & 0.17 \\
& & & & $(0.09)$ & $(0.60)$ & $\mathbf{( 0 . 0 0 0 1 )}$ \\
Mexico & Global aggregate & -- & -514.9 & 1029.3 & 0.001 & 0.21 \\
& Demand & -- & $(0.59)$ & $(0.57)$ & $(0.95)$ & $(0.08)$ \\
\multirow{2}{*}{ Norway } & Global aggregate & 0.19 & -55.6 & 4370.6 & 0.0006 & 0.35 \\
& Demand & $(0.09)$ & $\mathbf{( 0 . 0 0 5 )}$ & $(0.09)$ & $(0.99)$ & $\mathbf{( 0 . 0 0 0 1 )}$ \\
\multirow{2}{*}{ UK } & Global aggregate & 0.11 & -0.56 & 15276.3 & 14.8 & 0.30 \\
& Demand & $(0.54)$ & $(0.12)$ & $(0.41)$ & $(0.28)$ & $\mathbf{( 0 . 0 0 0 1 )}$ \\
& & & & &
\end{tabular}

Notes: See Table 2.

Table 9. Estimates for the linear model in equation (9) with nominal exchange rate returns for the four oil-market shocks from Kilian and Murphy's (2014) model

\begin{tabular}{lllll}
\hline \multirow{2}{*}{ Country } & Type of shock & \multicolumn{3}{c}{ Coefficient estimates } \\
\cline { 3 - 5 } & & $\alpha$ & $\beta_{1}$ & $\lambda_{1}$ \\
\hline \multirow{2}{*}{ Brazil } & Global aggregate & -- & -0.49 & 0.40 \\
& Demand & & $\mathbf{( 0 . 0 4 )}$ & $\mathbf{( 0 . 0 0 0 1 )}$ \\
& & & -0.25 & 0.37 \\
Norway & Idiosyncratic & -- & $\mathbf{( 0 . 0 4 )}$ & $\mathbf{( 0 . 0 0 0 1 )}$ \\
& & & &
\end{tabular}

Notes: See Table 3. 


\section{Appendix: Data Sources}

Monthly data are used. The world oil supply (crude oil production in millions of barrels per day) is taken from the US Energy Information Administration (EIA) at http://www.eia.gov/totalenergy/data/monthly/index.cfm. The percentage deviation from trend for the global real economic activity index is from Lutz Kilian's website at the University of Michigan http://www-personal.umich.edu/ lkilian/paperlinks.html. On the usefulness of this index for measuring real global economic activity, see Kilian and Zhou (2017). Data on US refiners' acquisition cost of crude oil are from http://www.eia.gov/petroleum/data.cfm\#prices.

Global crude oil inventories are defined as crude oil stocks in storage above the ground. They are approximated by OECD crude oil inventories. We updated the data available from Kilian and Murphy (2014) beyond August 2008. For this purpose, we used data from the EIA and data adjustments kindly supplied to us by Lutz Kilian. The OECD database does not report crude oil inventories but only petroleum inventories. Therefore, following Kilian and Murphy (2014), we scaled US crude oil inventories with the ratio of OECD petroleum stocks to US petroleum stocks. Kilian and Lee (2014) studied the reliability of using this proxy variable for crude oil inventories above the ground. They found that an alternative measure of inventories derived from proprietary data leads generally to similar results, despite the correlation between the two inventory measures being not very high.

Nominal exchange rates for Brazil, Canada, Mexico, Norway, and the UK are taken from the Federal Reserve Bank of St. Louis' FRED database, retrieved at http://research.stlouisfed.org/fred2/categories/15. Except for the UK, exchange rates are quoted as foreign currency per US dollar. For the UK, we inverted the exchange rate to make it directly comparable to that of the other countries. The CPI data were sourced from the OECD data web site: http://stats.oecd.org/Index.aspx?querytype=view\&queryname $=221$. The exchange rate between the Russian ruble and the US dollar was taken from Quandl (https://www.quandl.com/). The annual data on oil rents in Figure 2 (as of 18 March 2016) are from the World Development Indicators site at http://wdi.worldbank.org/table/3.15. Data for Russia are available from 1989 onwards. 